\title{
Experimental Study of Polarization Properties of Rough Surface
}

\author{
S. N. Svitasheva \\ Rzhanov Institute of Semiconductors Phy sics of RAS, ac. Lavrentiev Av. 13, Novosibirsk, 630090, Russia
}

\begin{abstract}
Singularities in behaviour of ellipsometric angles via functions of incidence angle of light were revealed experimentally under investigating four types of the samples manufactured on two materials: on dielectric-quartz and on metal-aluminium. Surface roughness was simulated by creation of artificial relief using a two-dimension orthogonal grating (random phase mask). Quadratic "defects" in the line were subjected to stochastic law of distribution. The "defects" were produced by etching in depth up to $1 \mu \mathrm{m}$ and their sizes were equal to $25 \times 25 \mu \mathrm{m}$ and $2.5 \times 2.5 \mu \mathrm{m}$ on each of materials. The impact of sizes of artificial "defects" and their density upon polarization of reflected light was investigated by the multip le-angles-of-incidence ellipsometric measurements at wavelength $0.63 \mu \mathrm{m}$. For the first time, a random phase mask was used for simulation of rough surface.
\end{abstract}

Keywords Roughness, Optical Properties, Ellipsometry

\section{Introduction}

The numerous attempts have been undertaken to find correlation between measurements of light scattering and the characteristics of surface roughness. Another but considerably more difficult approach is to solve the inverse scattering problem. A number of different empirical models of surface roughness have been used to characterize surfaces including sine grating, triangle grating (echelette), and rectangle grating[1-6]. Almost all above models converge to effective medium model (EMA). In this paper, we use, for the first time, the random phase mask model. The random phase (RPM) is a two-dimension orthogonal grating with the stochastic law $1 / 2 n+1$ distribution of square "defects" with sizes $a \times a$. Our calculations of the polarizing characteristics of the RPM, and discuss the influence of each of parameters of defects on polarizing angles had been described by author[7]. The analysis was carried out for multiple- angles-of- incidence (MAI) ellipsometric measurements. It is needed to reminder that ellipsometric angles are connected with well known Fresnel reflection coefficients for $p$ - and $s$-polarized light by the following relationship: $\mathrm{Rp} / \mathrm{Rs}=\rho \equiv \tan \Psi \exp (\mathrm{i} \Delta$ ), because Rp and Rs are complex values. Interest to similar experimental works had been caused by big quantity of investigations connected with plas mon effects [8-11].

Relationships obtained author[12-13] differ from

* Corresponding author:

Svitasheva@thermo.isp.nsc.ru (S. N. Svitasheva)

Published online at http://journal.sapub.org/eee

Copyright (C) 2012 Scientific \& Academic Publishing. All Rights Reserved formulae which were got by Heinz Raether[14] based on another theoretical prerequisites, although they look like as the similar.

Two purposes of this report are to establish correlation relationship between a priory known parameters of a relief and ellipsometric angles via functions of incidence angle of light, i.e. $\Psi\left(\varphi_{0}\right)$ and $\Delta\left(\varphi_{0}\right)$ and to explain observable experimental singularities of $\Psi\left(\varphi_{0}\right)$ and $\Delta\left(\varphi_{0}\right)$, on the basis of the analytical formulae for RPM model using results obtained earlier in $[7,15]$ by summation of all partial reflected and dissipated waves. Artificial roughness of surfaces was created by the etching through a two-dimension orthogonal grating with the stochastic law $1 / 2^{\mathrm{n}+1}$ distribution of square "defects" with a size $a \times a$. The high "defects" in horizontal lines had been organized into domains of various configurations [13]. The total areas of high and low domains are equal.

\section{Experimental Techniques}

In generally, reflected field from RPM is represented by superposition of the pictures which are turning out as a result of Fraunhofer diffraction on square aperture with most probable size $a[16]$. All measurements were carried out at wavelength of light $0.63 \mu \mathrm{m}$ under incidence angles $\varphi_{0} \in 45^{\circ}-88^{\circ}$ for the zero diffraction order only. Depths of a relief were varied from 0 up to $1.005 \mu \mathrm{m}$ and their values were supervised by interference microscope. The variation of depth of a relief means the changing of a few conditions: a) condition of interference of light reflected by top-bottom cell sides, b) condition of shadowing of bottom side of RPM elementary cell, c) condition of detecting of light 
scattered by cell sides. Last condition is valid in restricted region of angles of incidence of light as shown in Figure 1d. To understand the further reasoning, the top view of RPM is shown in Figure 1a; two variants of cross-section of relief etched in quartz or alu miniu m are shown in Figure 1b,c.

Changeover from one size of RPM cell to another (from $25 \times 25 \mu \mathrm{m}$ to $2.5 \times 2.5 \mu \mathrm{m}$ ) is equivalent to the changing in $\sim 100$ time of "defects" density on an investigated surface. Changeover from one material to another is equivalent to the changing at least in 20 times of intensity of a diffuse scattered light because the reflectivity of quartz is about $\sim 4 \%$, and of aluminium is $\sim 90 \%$ (at normal angle of incidence of the light and under the only one reflection).

Theoretical analysis clearly revealed, that intensity of the dispersed beams is insignificant also its contribution in mirror -component is poorly appreciable, except for special situations, for instance, near at Brewster's angle where reflection coefficient for $p$-polarized light is minimal (for metal) or equal to zero (for dielectric-quartz) or when the minimum of an interference of light reflected by the top and bottom sides is observed. Conditions of an interference are satisfied when $\Delta_{1}$ - the path-length difference of the beams reflected by the top and bottom sides, is multiple $n \pi$. These conditions are valid at incidence angle $\varphi_{\text {interferen }}$.

$$
\begin{aligned}
& \Delta_{1}=4 \pi \cos \varphi_{0} d / \lambda=n \pi \\
& \varphi_{\text {interferen }}=\arccos (\lambda n / 4 d), n=1,3,5 \ldots
\end{aligned}
$$

\section{Experimental Results}

Samples have been situated on ellipsometer table so that a line of "defects" coincided with the plane of incidence of the light, and corresponded to theoretical analysis of model. It was found that depth of artificial relief dramatically impact upon characteristics of reflected light.

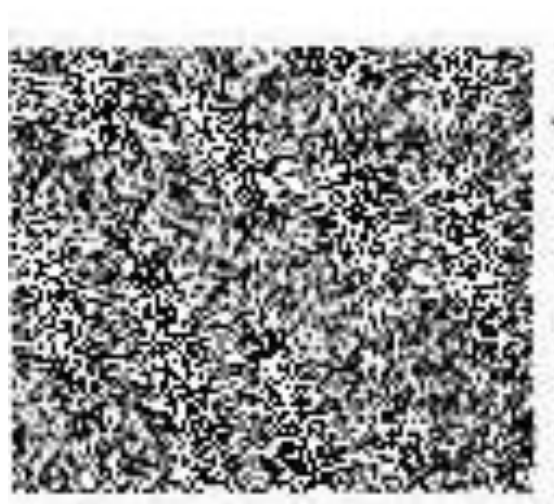

a
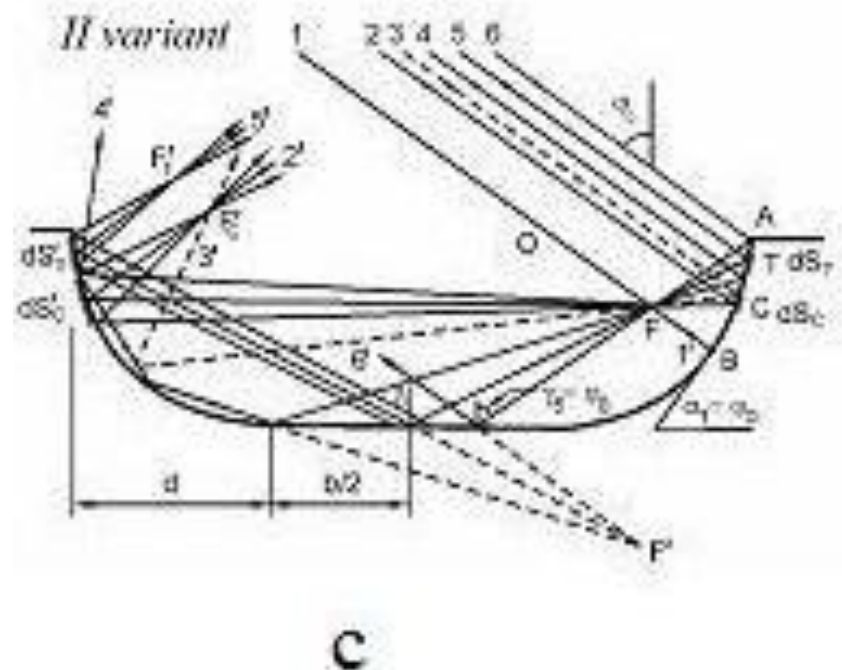

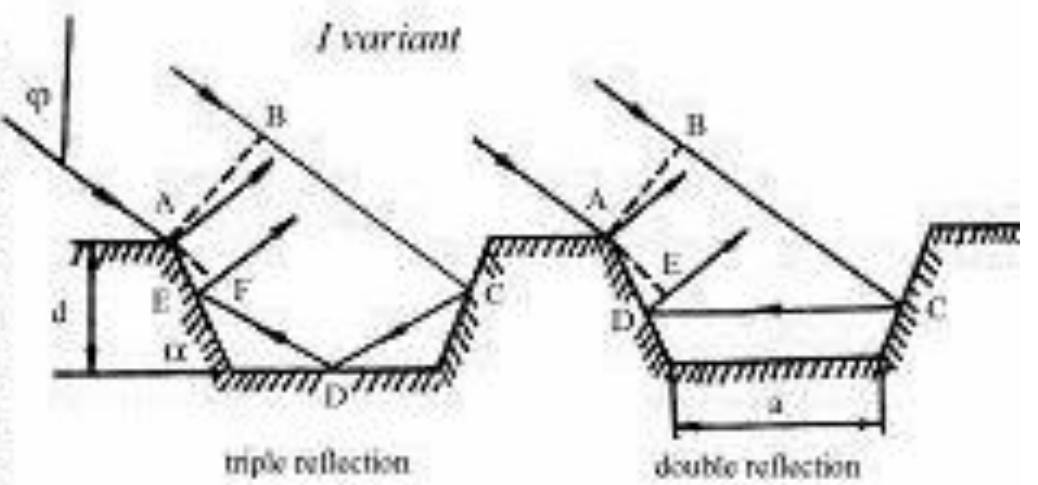

b
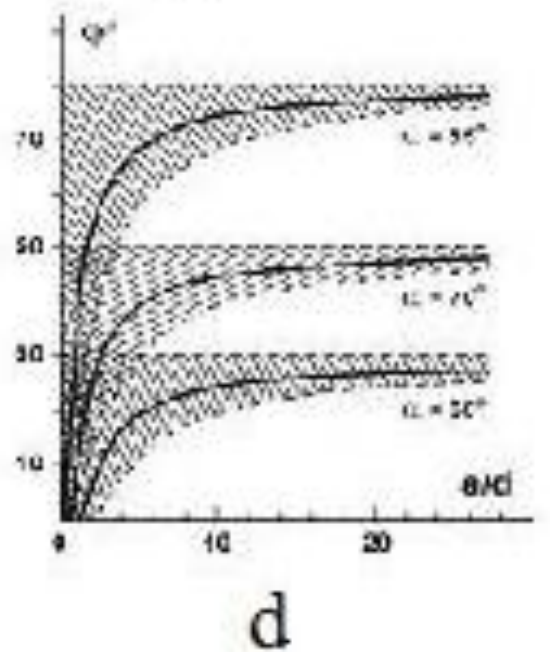

Figure 1. a) Top view of RPM; b,c) Two possible schemes of light reflection by elementary cell; d) Dependence of incidence angles of light $\varphi_{0}$, at which light is scattered in zero direction, on value of $a / d$ and $\alpha$, i.e. on geometry of RPM cell: $a \times a$ is size of top side, $d$ is its depth and $\alpha$ is inclining angle of lateral side; solid lines correspond to maximum of light scattered by three sides of PRM cell 


\subsection{Small Depth of Relief}

Until depth of artificial relief is small $(\mathrm{d} \in 20 \div 110 \mathrm{~nm})$ and mutual suppression of rays of light reflected by top-bottom sides does not occur, $\Psi\left(\varphi_{0}\right)$ and $\Delta\left(\varphi_{0}\right)$ polarization characteristics of light reflected by surface with artificial "defects" slightly differ from the same characteristics of smooth surface, as shown in Figure 2. The density of "defects" essentially enhances these differences provided that relief depths fit in almost the same limits. For example, in case of $\mathrm{Al}$, both minimal value of $\Psi$ at Brewster angle and value of principal angle at $\Delta=\pi / 2$ are changed in bounds of a few degrees (Fig. 3).
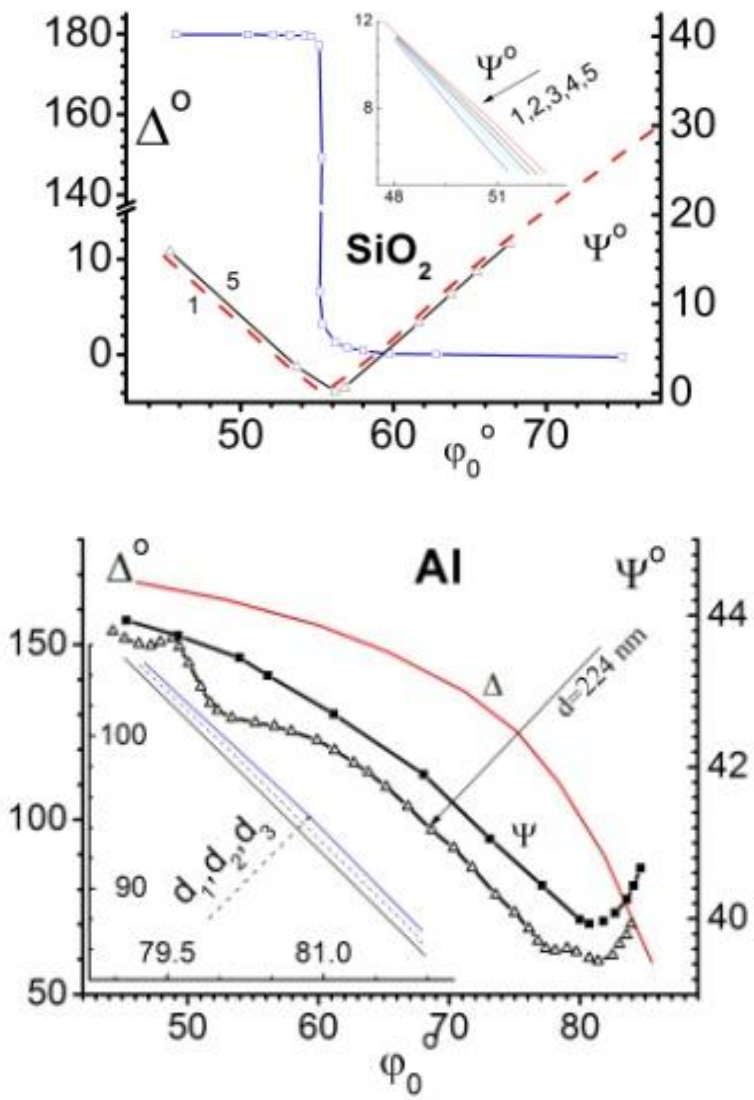

Figure 2. Comparison of experimental dependences of $\Delta\left(\varphi_{0}\right)$ and $\Psi\left(\varphi_{0}\right)$ both for fused quartz and aluminium: the size of RPM element ary cell on a surface is equal $25 \times 25 \mu \mathrm{m}$; depth of a relief: $d_{1}=20 \mathrm{~nm}, d_{2}=40 \mathrm{~nm}, d_{3}=50$ $\mathrm{nm}, d_{4}=80 \mathrm{~nm}, d_{5}=110 \mathrm{~nm}$. In the insert in lager scale $\Psi$ for quartz and $\Delta$ for aluminium are shown

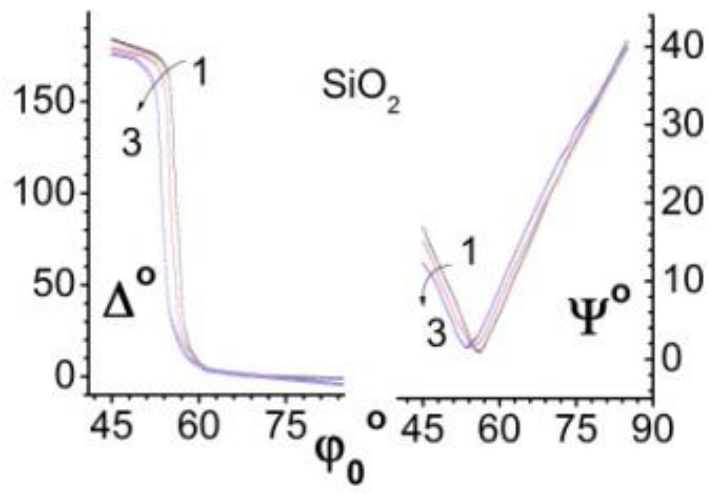

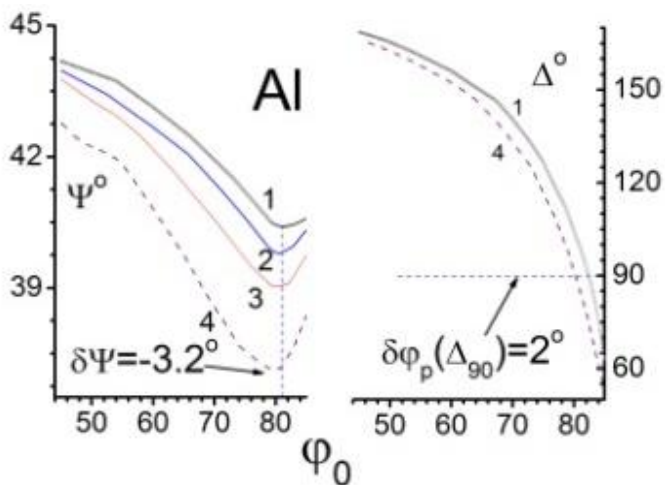

Figure 3. Comparison of experimental dependences of $\Delta\left(\varphi_{0}\right)$ and $\Psi\left(\varphi_{0}\right.$ : the size of elementary cell RPM on a surface is equal $\mathbf{2 . 5 \times 2 . 5} \mu \mathrm{m}$; depth of a relief: for fused quartz $d_{1}=103 \mathrm{~nm}, d_{2}=143 \mathrm{~nm}, d_{3}=208 \mathrm{~nm}$; for aluminium $d_{1}=0 \mathrm{~nm}, d_{2}=55 \mathrm{~nm}, d_{3}=103 \mathrm{~nm}, d_{4}=143 \mathrm{~nm}$

\subsection{Relief Depth Closed to $\lambda / 4$}

As soon as depth of artificial relief becomes sufficient for suppression of rays of light reflected by top-bottom sides, singularities in $\Psi\left(\varphi_{0}\right)$ and $\Delta\left(\varphi_{0}\right)$ - polarization characteristics are arose (Fig.4).

In case of dielectric, the changing in $\Delta$ is larger than in $\Psi$ due to low reflectivity of quartz so graph used coordinates $\Delta-\varphi 0$ and $\delta \Psi-\varphi 0$. Contrary, in case of metal the amplitude changing is larger than the changing in phase because reflectivity of $\mathrm{Al}$ is great; and coordinates $\delta \Delta-\varphi 0$ and $\Psi-\varphi 0$ is used for graph.
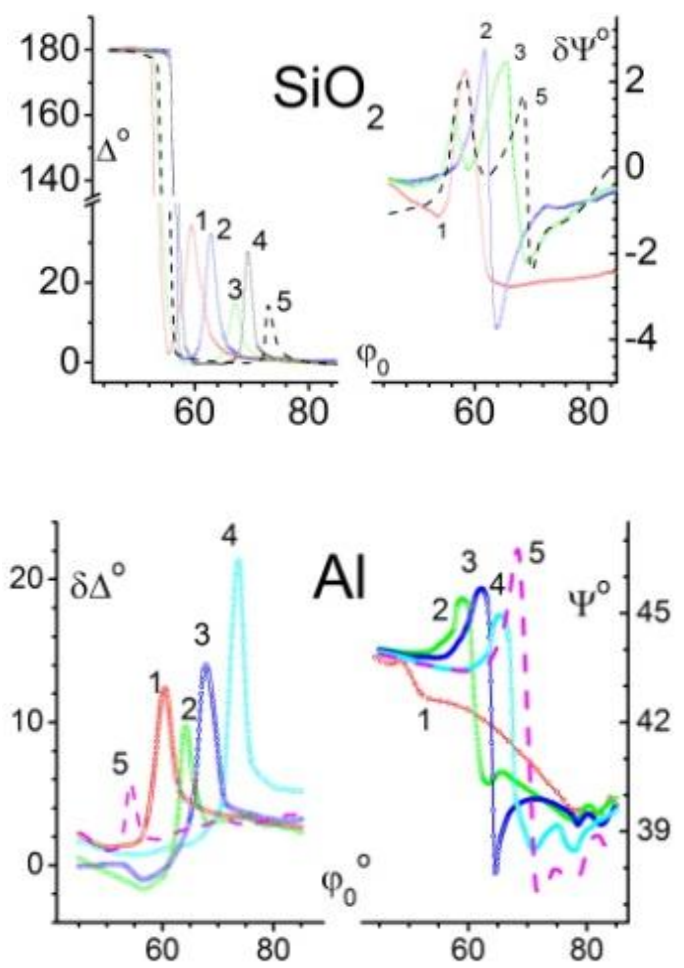

Figure 4. Comparison of experimental dependences of $\Delta\left(\varphi_{0}\right)$ and $\delta \Psi\left(\varphi_{0}\right)$ for fused quartz but $\delta \Delta\left(\varphi_{0}\right)$ and $\Psi\left(\varphi_{0}\right)$ for aluminium: the size of elementary cell RPM on a surface is equal $25 \times 25 \mu \mathrm{m}$; depth of a relief: $d_{1}=316 \mathrm{~nm}, d_{2}=351 \mathrm{~nm}, d_{3}=413 \mathrm{~nm}, d_{4}=461 \mathrm{~nm}, d_{5}=572 \mathrm{~nm}$. There are second extrema in dependences for 3-5 samples 


\subsection{Impact of "Defect" Density}

The increasing of "defect" density results in proportional changes of both $\Psi\left(\varphi_{0}\right)$ and $\Delta\left(\varphi_{0}\right)$ as shown in Figure 5. Besides, in case of Al, peak widths in $\Psi\left(\varphi_{0}\right)$ and $\Delta\left(\varphi_{0}\right)$ are greater than in the event of fused quartz though sizes of "defect" are the same. The last experimental fact is result of great reflectivity of metal Al.
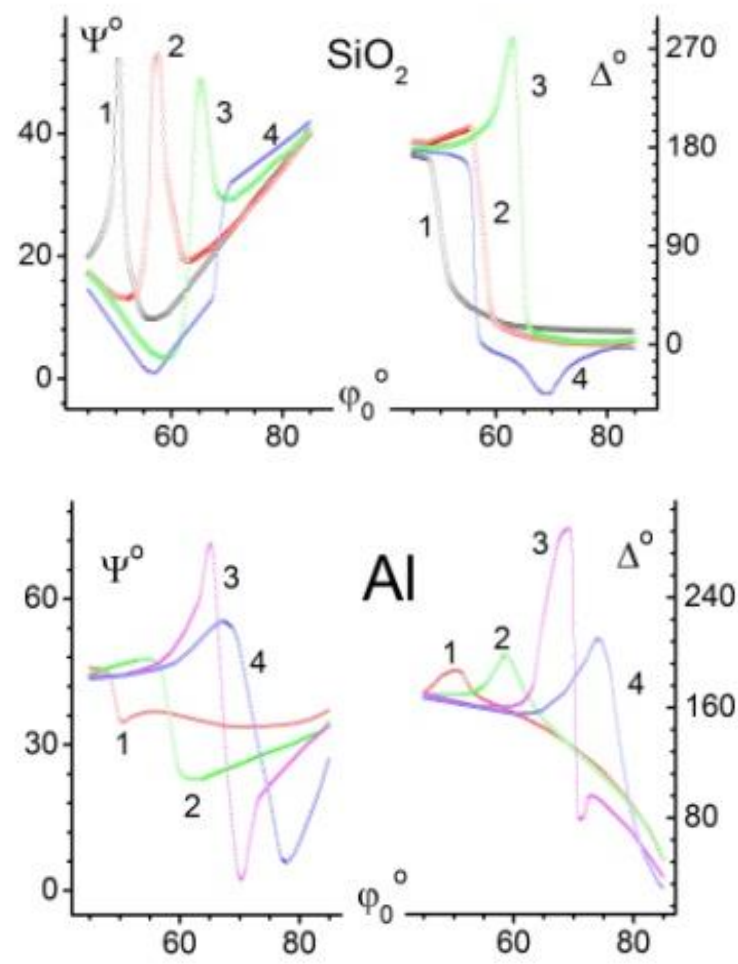

Figure 5. Comparison of experimental dependences of $\Delta\left(\varphi_{0}\right)$ and $\Psi\left(\varphi_{0}\right)$ for fused quartz and for aluminium: the size of elementary cell RPM on a surface is equal $2.5 \times 2.5 \mu \mathrm{m}$; depth of a relief: $d_{1}=250 \mathrm{~nm}, d_{2}=306 \mathrm{~nm}$, $d_{3}=350 \mathrm{~nm}, d_{4}=408 \mathrm{~nm}$

\subsection{Large Depth of Relief}

Further increasing of depth of relief leads to enhancing of shadowing effect and decreasing of intensity light dispersed in zero order (or mirror direction), i.e. to the weakening of its contribution in photo-detector window. The shadowing becomes so large that contribution of light scattering by lateral and bottom sides takes negligible small value and amplitude changing (in ellipsometric angle $\Psi$ ) is almost no different in compare with smooth surface. While phase changing (in ellipsometric angle $\Delta$ ) is so noticeable that they do not look like on all previous dependences of $\Delta(\varphi 0)$

as shown in Figure 6 (upper) and the largest changing of phase angle $\Delta$ is observed at small angles of incidence of light. Besides, as seen from the same Figure, the Brewster's angle brings noticeable distortion in polarization characteristics of light reflected from fused quartz because p-component becomes to zero. Situation is abruptly changed for analogical defects etched in aluminium: the changing in $\Psi$ and in increments of $\Delta$ are the same as shown in Figure 6 (lower). Influence of the Brewster's angle for metal also is apparent; the pseudo-Brewster's angle for alu miniu $\mathrm{m}$ is approximately equal to $81^{\circ}$ and there are singularities in $\Psi$-the amplitude polarization angle near $81^{\circ}$ as shown in Figure 6 (lower). Unfortunately, it is impossible to prepare artificial roughness with cell size $2.5 \times 2.5 \mu \mathrm{m}$ by etching into depth up to $1 \mu \mathrm{m}$. Because, size of top side of every cell is decreased to value of double depth provided that etching is is otropic.
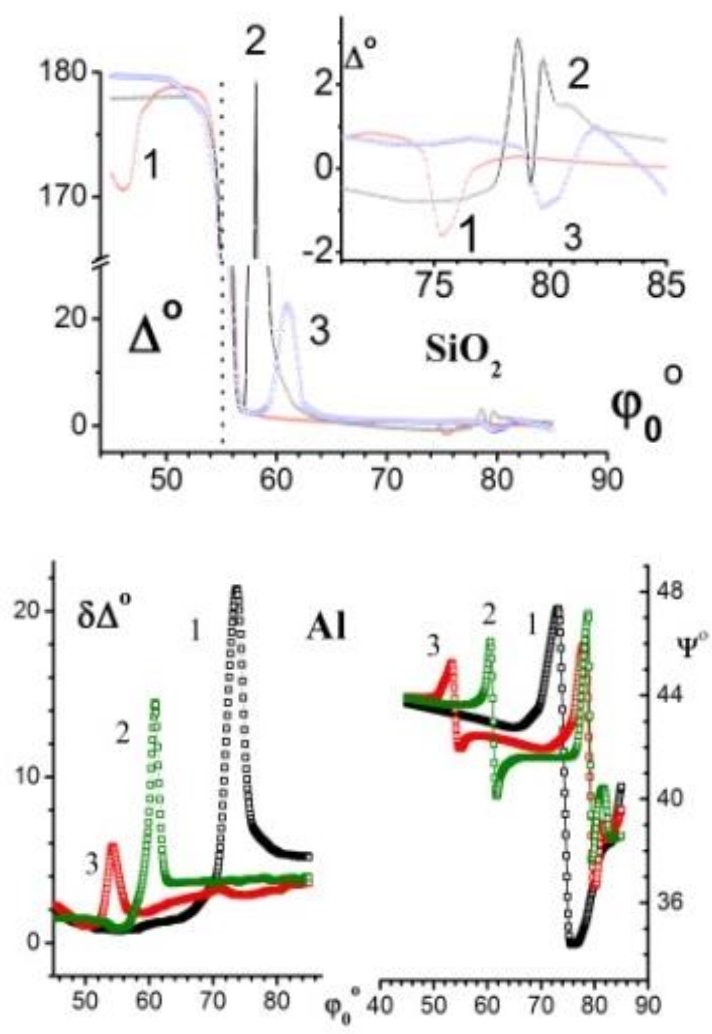

Figure 6. Dependences of phase angles of complex relative refractive index on incidence angle of light $\Delta\left(\varphi_{0}\right)$ when depth of relief exceeds quarter of wavelength of light. The changing in amplitude angle $\Psi$ due to artificial roughness is negligible and it is not shown here. Depths of defects in fused quartz are following: $d_{1}=690 \mathrm{~nm}, d_{2}=904 \mathrm{~nm}, d_{3}=1005 \mathrm{~nm}$. The behavior of extrema of higher order is shown in details on the insert. Size of elementary cell is $25 \times 25 \mu \mathrm{m}$. Brewster's angle is noted by dot line; Dependences of amplitude angles $\Psi\left(\varphi_{0}\right)$ and increments of phase angles $\delta \Delta\left(\varphi_{0}\right)$ of complex relative refractive index on incidence angle of light $\varphi_{0}$ when depth of relief exceeds quarter of wavelength of light. The changing in $\Psi$ due to artificial roughness is comparable with changing in the increment of $\delta \Delta$. Depths of defects in aluminium are following: $d_{1}=572 \mathrm{~nm}$, $d_{2}=791 \mathrm{~nm}, d_{3}=1005 \mathrm{~nm}$. Size of element ary cell is $25 \times 25 \mu \mathrm{m}$

Therefore the same relief differently impacts upon the polarization characteristics of light reflected from a surface of metal and dielectric, as apparently from a Figure 3-6.

\section{Experiment Confirms Theory}

Summarizing all experimental measurements to validate correctness of theoretical analysis[7] consider how way values of depth of artificial defects impact on polarization of light reflected from rough surface in Figure 7, i.e. when singularities occur in $\Delta\left(\varphi_{0}\right)$ and $\Psi\left(\varphi_{0}\right)$ dependences. 
Experimental measurements carried out on two sets of sample consisting from different materials: dielectric-fused quartz and metal- aluminium are very closely coincided with two curves calculated from interference conditions and with taking account of defect's depths which were measured by independent technique

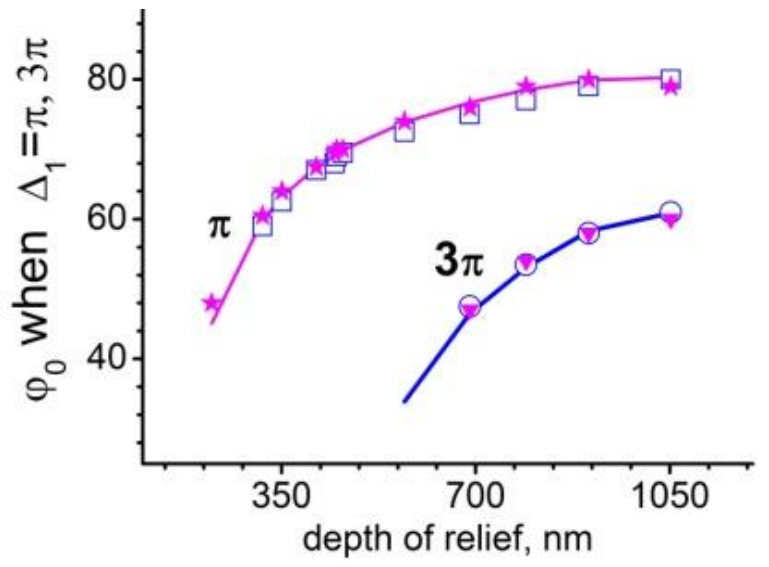

Figure 7. Values of angle of incidence calculated from interference condition (solid lines) in according with expression (1); and experimental values of singularities (extrema in $\Psi\left(\varphi_{0}\right)$ and $\Delta\left(\varphi_{0}\right)$ dependences) for quartz: $\forall$ and $--25 \times 25 \mu \mathrm{m}$ and $2.5 \times 2.5 \mu \mathrm{m}$, respectively; and for aluminium: $\psi$ and $\Delta-25 \times 25 \mu \mathrm{m}$ and $2.5 \times 2.5 \mu \mathrm{m}$, respectively

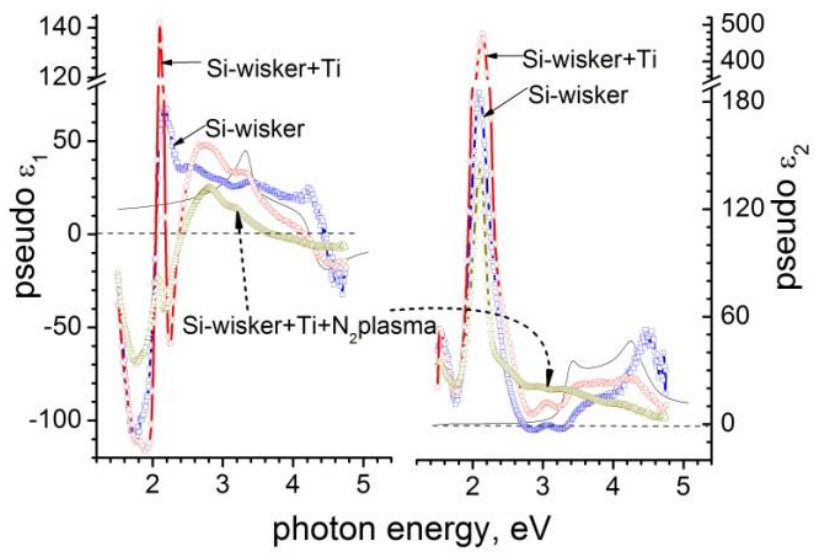

Figure 8. Spectral dependences of optical properties (real $\varepsilon_{1}$ and imaginary $\varepsilon_{2}$ parts of pseudodielectric function) for $\mathrm{Si}$ (bold lines) of Si-nanowhiskers structure (line+ symbols) grown by MBE technique with great length of whiskers $(580 \div 990 \mathrm{~nm})$ before and after deposition of $\mathrm{Ti}$ films (76 $\AA$ ) and, then after deposition of T iN films (146 $)$

The random phase mask is coarse model of a rough surface: size of squire "defects" is great $(a » \lambda)$, though distribution of defects is subjected to the binomial law of distribution, but their depth is identical, therefore interference effects are brightly exhibited if defect's depth exceeds quarter of wavelength, i.e. at $d>\lambda$ 4. However, even within the limits of such coarse model for s mall depth of artificial relief RPM $(d<\lambda 4)$, the changes of experimental dependences $\Delta\left(\varphi_{0}\right)$ and $\lambda\left(\varphi_{0}\right)$ overlap with the similar dependences obtained on polished surfaces [17, 18]. As for author opinion, similar approach could be applied to some metamaterials [19]; where, for example, experimentall y was demonstrated independence of energy position (near $2 \mathrm{eV}$ ) of false absorption peak in transparency region of silicon after films of titanium and titanium nitride were deposited. While the magnitudes of $\varepsilon_{1}$ and $\varepsilon_{2}$ are undergone to great deformations; these changing are impossible in the case for surface plasmons.

\section{Conclusions}

Random Phase Mask which was suggested here as model of rough surface, has allowed to explain and to predict singularities in experimental polarization dependences of $\Delta\left(\varphi_{0}\right)$ and $\lambda\left(\varphi_{0}\right)$.

Conditions of the maximal influence of a diffused light on polarizing characteristics of rough surface are found out: a) when interference condition is fulfilled or/and b) when reflection of $p$-polarized light is vanished for dielectric (or is minimal for metal) at Brewster's angle. Presence of extrema in dependences of $\Delta\left(\varphi_{0}\right)$ and $\lambda\left(\varphi_{0}\right)$ is common phenomenon for both dielectric and metal materials, it is caused by an interference of light reflected and light diffused; and only defect's depths define positions of these extrema. The differences (magnitude and width of extrema and their a mount) in a state of polarization of light reflected from an artificial rough surface with irregular relief are defined by reflectivity of material only. The basic common behaviours and their differences are theoretically predicted and experimentally verified for dielectric and metal.

These results can be useful to definition of the sizes of test structures in integrate circuit, for instance.

\section{ACKNOWLEDGEMENTS}

Author deeply appreciates to paper of Azzam R.M.A. and Bashara N.M.[1] which attracted attention of many investigators and created new direction in ellipsometry field named as diffraction ellipsometry [20].

\section{REFERENCES}

[1] Azzam R.M.A. and Bashara N.M. "Polarization characteristics of scattered radiation from a diffraction grating by ellipsometry with application to surface roughness", Phys. Rev. B, v.5, N12, p.4721, 1972.

[2] Elson J.M., Bennett J.M., "Relation between the angular dependence of scattering and the statistical properties of optical surfaces”, J. Opt. Soc. Am., v.69, N1, p. 31, 1979.

[3] Vorburger T.V., Ludema K.C., "Ellipsometry of rough surfaces", Applied Optics, v.19, N4, p.581, 1980.

[4] Maradudin A.A., Mills D.L., "Scattering and absorption of electromagnetic radiation by a semi-infinite medium in the presence of surface roughness", Phys. Rev. V. 11, p. 1392, 1975. 
[5] Fenstermaker C. A. and McCrackin F. L., "Errors arising from surface roughness in ellipsometric measurements of refractive index of a surface", Surface Science, 16 p.85, 1969.

[6] Rzhanov A. V., Svitasheva S. N., Svitashev K. K., "Graphical method of interpretation of ellipsometric measurements on rough surface", Doklady of USSR Academy of sciences , 273 1123, 1983.

[7] Svitasheva S.N. Random Phase Mask as Model of rough surface. Part I Theory-//Thin Solid Films v. 519 p.2718-2721, 2011; DOI: 10.1016/j.tsf.2010.11.070.

[8] Losurdo M., Brown A. S., Bruno G. "Graphene and Plasmonics: the Nanoscale Challenges for Real-time Spectroscopic Ellipsometry" E-MRS 2012 Fall Meeting, $\mathrm{K}-\mathrm{X}-1$ : www.european-mrs.com.

[9] Franta D., Nečas D., Zajíčková L., Ohlídal I. “Advanced modelling for optical characterization of thin films: structural and dispersion models" E-MRS 2012 Fall Meeting, $\mathrm{K}-\mathrm{X}-2$ : www.european-mrs.com.

[10] King Tai Cheung, Chap-Hang To, Yishu Foo, and Zapien J. A. "Towards quantitative optical modeling in nanostructures" E-MRS 2012 Fall Meeting, K-VII-1: www.european-mrs.com.

[11] Montgomery P. C. "Far field optical nanoscopy: how far can you go in nanometric characterization without resolving all the details?" E-MRS 2012 Fall Meeting, K-VI-1: www.european-mrs.com.

[12] Svitasheva S. N., Lubinskaya R. I., "Models of rough surface, and polarization characteristics of light reflected from it", Preprint 11-87, Institute semiconductor physics, Siberian Branch, Academy of sciences USSR, p.1-48, 1987.
[13] Svitasheva S. N., Soldatenkov I. S., "Experimental dependences of $\Psi$ and $\Delta$ on incidence angle of lighton the surface of Random Phase Mask", Preprint 12-87, Institute semiconductor physics, Siberian Branch, Academy of sciences USSR, p.1-48 1987.

[14] Raether Heinz, "Surface Plasmons on Smooth and Rough Surface and gratings", Springer-Verlag Berlin, Heidelberg, 1-133, 1988.

[15] Svitasheva S. N. Random Phase Mask as Model of rough surface. Part II Experiment-// Thin Solid Films v. 519 2011, p.2722-2724; DOI information: 10.1016/j.tsf.2010.11.067.

[16] Born M., Wolf E, "Principal of Optics. Electromagnetic theory of propagation, interference and diffraction of light", 2nd edition, Pergamon Press \$8.5, 1964.

[17] Svitasheva S.N., Svitashev R.R., Semyonov E.V., Vasilyev A. G., "Evolutions of ellipsometric parameters due to the mechanical processing of solid surface", Surface. Physics, chemistry, mechanics, 12 64-71, 1983.

[18] Rzhanov A. V., Svitasheva S. N., Svitashev K. K., Sokolov V. K., Ashkerov Yu. V., Osadchev L. A., Tsesneck L. S., "Ellip sometric method of determination of quality of surface polished", Doklady of USSR Academy of sciences, 267, p.373, 1982 .

[19] Svitasheva S. N., Sokolov L. V., Zakharov N. D., Werner P., "Spectroscopic ellipsometric method for characterization of metamaterials", The 5th International Conference on Spectroscopic Ellipsometry, University at Albany, Albany, NY USA, abstract №197, 2010.

[20] Egorova G. A., Lonskii Eu. S., Potapov Eu. V., Rakov A. V., "Ellipsometry of light diffracted", Microelectronics (Russian), 9, issue 4, p.319, 1980. 